\title{
The Role of Heuristic Methods as a Decision-Making Tool in Aggregate Production Planning
}

\author{
Mahmood B. Ridha ${ }^{1}$ \\ 1 Department of Business Administration, Faculty of Economic and Administrative Sciences, Al-Zaytoonah \\ University, Amman, Jordan \\ Correspondence: Dr. Mahmood B. Ridha, Department of Business Administration, Faculty of Economic and \\ Administrative Sciences, Al-Zaytoonah University, Amman 11733, P.O. Box 130, Jordan. E-mail: \\ m.alobidi@zuj.edu.jo
}

Received: January 31, 2015

Accepted: February 27, $2015 \quad$ Online Published: March 2, 2015

doi:10.5430/ijba.v6n2p68

URL: http://dx.doi.org/10.5430/ijba.v6n2p68

\begin{abstract}
This study aims to explain the role of heuristic methods in the decision making process and as a tool for knowledge capture. As a result, we conclude that heuristic methods give better support to the decision maker than mathematical models in many cases especially when time and cost are critical factors in decision making.
\end{abstract}

Keywords: heuristic method, production planning, decision making, dynamic programming

\section{Introduction}

Many studies indicate that Arab managers do not utilize quantitative methods in decision making (Ahmed, 1998, Alshaikh, 1993, Alsameraai, 1999, Alsameraai, 2003, Yusef, 1991). The result is poor quality of decisions and low efficiency and less effective performance of Arab organizations. The Arab managers used traditional methods like (personal judgment, trial by error, past experience... etc.). This study aims to familiarize Arab managers with heuristic methods as simple quantitative methods but more effective and efficient than traditional methods and more user -friendly in comparison with mathematical models.

\section{Production Planning}

Production planning is one of the classical problems in Operations Research and has received considerable attention from both academia and industry during the last two decades (Gaither, 2002, Heizer, 2004, Krajewski, 2002, Naylor, 2002). Production planning has received much attention in the literature. Many different approaches to the problem have been suggested. These can be categorized into three main areas:

- Optimal approach,

- Heuristic rules,

- Artificial intelligence application.

In this research we deal with the heuristic approach to determine production rates. We will focus on aggregate plan that specifies how the company will work for the next periods or so toward those goals within existing equipment and facility capacity constraints.

Among the managerial activities, production planning is probably the most complex (Gaither, 2002, Heizer, 2004, Krajewski, 2002, Naylor, 2002). The complexity of the planning activity stems from two main factors. The first is turbulence of the environment that introduces frequent disturbances as a result of demand fluctuation, changes in commercial priorities, raw materials availability and production capabilities. Therefore production planning is a highly dynamic activity and these leads to a tendency for a short term view. Secondly, there are numerous factors and objectives that have to be considered, the most important of which can be grouped as follows:

- To maintain a smooth and stable production pattern and to keep slack in order to be able to accommodate alterations imposed by disturbances, due to demand change.

- To maintain appropriate end products inventory levels so that inventory outages and delays in meeting customer's orders are avoided. 
- To keep costs as low as possible by reducing inventory and through full plant utilization. The translation of these objectives into operational forms within the planning activity is very difficult.

From the above mentioned factors, we can say that production planning involves many complex problems where the decision maker is confronted with conflicting objectives under the presence of scarce resources. The particular problem the production manager faces in production planning is the determination of how much to produce and when to produce.

This problem is particularly difficult in production to order where demand for the products is highly uncertain and there is no possibility for having substantial stocks on hand. Therefore it is necessary to assume that most production to order plants can only plan from customers order backlogs. The basic objective of production planning is meeting demand and minimizing the total cost of decisions over a finite number of periods in the future. The number of periods can be four weeks, a month or a quarter but more commonly it ranges from six months to a year.

\section{Principal Notions}

The following are notions used in this study:

- $\mathrm{t} \quad=$ discrete time $(\mathrm{t} \varepsilon \mathrm{N})$;

- $\mathrm{D}_{\mathrm{t}} \quad=$ customers' orders in period $\mathrm{t}$;

- $\mathrm{PR}_{\mathrm{t}}=$ production rate in period $\mathrm{t}$;

- $\mathrm{PC}_{\mathrm{t}}=$ maximum production capacity

- $\mathrm{SC}_{\mathrm{t}}=$ maximum storage capacity in

- $\mathrm{S} \quad=$ inventory level;

- $\mathrm{CS}_{\mathrm{t}}=$ costs of set up in period $\mathrm{t}$;

- $\mathrm{CP}_{\mathrm{t}}=$ variable production unit costs;

- $\mathrm{CH}_{\mathrm{t}}=$ holding unit costs in period $\mathrm{t}$;

- $\mathrm{TC}_{\mathrm{t}}=$ total cost in period $\mathrm{t}$;

- $\mathrm{i}=$ counter for time.

Out of many problems that manufacturing firms face in production planning, we have chosen the following features of production planning problem that form the basis for all experiments:

- Planning horizon includes $(0<\mathrm{t}<6)$

- $\mathrm{D}_{\mathrm{t}}$ for $(0<\mathrm{t}<6)$ are known,

- Initially, all resources for production are available for $(0<\mathrm{t}<6)$,

- $\quad \mathrm{PC}_{\mathrm{t}}, \mathrm{SCt}$ are available and fixed for $(0<\mathrm{t}<6)$,

- $\mathrm{SC}_{\mathrm{t}}>\mathrm{PCt}$ for $(0<\mathrm{t}<6)$,

- $\mathrm{S}_{0}$ at the beginning of the first period should be zero,

- $\mathrm{S}_{\mathrm{t}}$ at the end of the last period should be zero,

- $\mathrm{CP}_{\mathrm{t}}, \mathrm{CS}_{\mathrm{t}}, \mathrm{CH}_{\mathrm{t}}$ are known for $(0<\mathrm{t}<6)$,

- $\mathrm{CH}_{\mathrm{t}}<\mathrm{CS}_{\mathrm{t}}$ for $(0<\mathrm{t}<6)$,

- $\mathrm{D}_{\mathrm{t}}$ for $(0<\mathrm{t}<6)$ should be produced and backlog in each period should be zero,

- $\quad \sum_{t=1}^{6} D_{t} \leq \sum_{t=1}^{6} P C_{t}$

- Released $\mathrm{D}_{\mathrm{t}}$ for $(0<\mathrm{t}<6)$ should be shipment in the last of its period,

- $\mathrm{TC}_{\mathrm{t}}=\mathrm{CS}_{\mathrm{t}}+\mathrm{CP}_{\mathrm{t}}\left(\mathrm{PR}_{\mathrm{t}}\right)+\mathrm{CH}_{\mathrm{t}}\left(\mathrm{S}_{\mathrm{t}}+\mathrm{PR}_{\mathrm{t}}-\mathrm{D}_{\mathrm{t}}\right)$ for $(0<\mathrm{t}<6)$.

- One production run should be scheduled in each period.

According to the above mentioned assumptions, the problem of this research is "How the production manager can meet all customers' orders over six periods without delay, by using fixed resources, and keeping total costs at a 
minimum". The variables of the problem are "customers' orders, production level and inventory level. And the parameters are production and storage capacity, setup cost, variable production cost and holding unit cost.

\section{The Concept and Characteristics of Heuristic Methods}

One of the quantitative methods is called a heuristic, which is used to solve a given problem by searching for reasonable and quick answers. A heuristic can be defined as any means, particularly a rule, principle or procedure intended to facilitate problem solving (Anderson, 2003, Goodwin, 2004, Klein, 1991, Leong, 1990, Smith, 1990). In other words, taken to its logical limit a heuristic is a rule of thumb. The heuristic solution process relies on intuitive or empirical rules, which, when applied to the problem, provide one or more solutions.

The heuristic approach has become increasingly popular in recent years as a fast method of obtaining good solution but not necessarily the optimal ones. It has been noted that managers generally look for adequate rather than optimal solution to their problems (Guignar, 1992, Hillier, 1990, Lawrence, 2002, Render, 2003, Taylor, 2007, Wästlund, 2015).

It is now recognized that one important way to improve management decision making without finding optimal solution is using the heuristic method (Lawrence, 2002, Heizer, 2004). It is widely used in management decision making to combat problems of size because, even with computers it is rarely possible to conduct an exhaustive evaluation of all possibilities, as a means of discovering the good or optimal solution (Anderson, 2003, Smith, 1990, Render, 2003, Taylor, 2007, Teale, 2003, Turban, 1990, Wisniewski, 2006). It may also be applied when the time or / and cost required to find optimal solution for the problem is likely to be high (Goodwin, 2004, Alvarado-Valencia, Barrero, 2014). One of the areas in which a heuristic provides either the only feasible or the best method of analysis is production planning. Many heuristic rules are developed by researchers in this field. In production planning, the basic idea of any heuristic is to analyze the structure of major decisions which determine how customer's orders are transformed into production plans. If we can represent this structure with fair precision by few a simple rules, we may be able to get a good representation. This representation may be adequate for planning purpose. However, unlike many quantitative techniques, the heuristic gives the production manager a significant amount of freedom to compose production plans that take into account features that he believes are important.

Since the methodology pursued in finding solutions is not difficult to understand it is likely to be employed. Moreover, since the heuristic method does not require special mathematical skills, it is widely used in solving practical decision making problems (Hauser, 2014, Hu, Z., Wang, 2014, Pendharkar, ,2015).

The general characteristics of the heuristic can be understood from close scrutiny of the strategies of building any heuristic. The following four strategies are involved in building a heuristic:

- The construction strategy,

- The improvement strategy,

- The component strategy,

- The learning strategy.

The input for method based on this strategy is nothing more than the data defining a specific instance of the problem. A solution is built up one component at a time. On other hand, the input for the second strategy is a solution to the problem. This solution is then progressively improved by the application of a series of modification. The component analysis strategy is used when the problems are so large or/and so complicated that the only practical approach is to break them up into manageable portions. Some times these portions are then dealt with independently by heuristics or even algorithms. And the solutions for portions are then married to form master plan. The fourth strategy used a tree - search diagram to chart their progress. That is, the different options which appear at various stages are represented by different branches of a tree. The sequences of choices actually made can be traced by a path through the tree, and the choice of which branch to take is guided by learning from outcome of earlier decisions (Bang, etl, 2014). From the above we can conclude that heuristic thinking does not necessarily proceed in a direct manner. It involves searching, learning, evaluating, judging and then again searching, relearning, and reappraisal as exploring and probing take place. The knowledge gained from success or failure at some point is feed back and modifies the search process (Maashi, etl, 2015).

Each of these strategies has its own desirable characteristics. It is necessary to account for the desirable characteristics in designing any heuristic for a specific problem. These desirable characteristics include:

- Simplicity of both design and computational requirement, 
- Execution in reasonable computational time,

- Solutions which are close to optimality,

- Only a small probability of any one solution being far below optimality.

The major advantages of a heuristic are as follows:

- Is simple to understand and therefore is easier to implement,

- Helps in training managers to be creative and come up with heuristic for other problem,

- Saves formulation time,

- Produces multiple solutions.

\section{Algorithm of Applied Model}

The objective of this model is to ascertain that all customers' orders are scheduled for production in such a way that due dates are met as well as being possible, while the total cost is kept low.

The model consists of four heuristic rules which are used to solve the problem of research. The output of this model will be obtained by comparing the results of each heuristic rule and the heuristic that meets all customers' orders with minimum total cost will be selected. Links will be established between the four heuristics in such a way that if any one of these fail, it is possible to return to the previous one. Furthermore more we compare the results from the heuristic with results from dynamic programming model to determine the efficiency of the heuristic model.

\subsection{Heuristic 1 (Hl)}

In this heuristic, demand and production capacity are compared on a monthly basis to determine the level of production. These are used as level of production.

The algorithm is as follows:

If

$$
\mathrm{D}_{\mathrm{t}}<\mathrm{PC}_{\mathrm{t}} \quad \text { for }(\mathrm{t} \varepsilon \mathrm{N})
$$

Then

$$
\mathrm{PR}_{\mathrm{t}}=\mathrm{D}_{\mathrm{t}}
$$

else

$$
\mathrm{PRt}=\mathrm{PCt}
$$

\subsection{Heuristic 2 (H2)}

In the second heuristic the solution is calculated using the demand of two months and production capacity. It consists of three cases which illustrate the valley and peak of demand of two periods. Three procedures are formed to find the desired production level. When the conditions of the procedure are not met $(\mathrm{Hl})$ will be used.

The descriptions of the cases and algorithm for the procedures are as follows:

Case 1: (the total demand for two periods is equal to or less than production capacity of the present Period)

Procedure P1:

$$
\begin{aligned}
& \mathrm{PR}_{\mathrm{t}}=\mathrm{D}_{\mathrm{t}}+\mathrm{D}_{\mathrm{t}}+1 \\
& \mathrm{PR}_{\mathrm{t}}+1=0
\end{aligned}
$$

Case 2: (the demand valley in the present period and demand peak in the next period are at equilibrium).

Procedure P2:

$$
\begin{aligned}
& \mathrm{PR}_{\mathrm{t}}=\mathrm{PC}_{\mathrm{t}} \\
& \mathrm{PR}_{\mathrm{t}}+1=\mathrm{PC}_{\mathrm{t}}+1
\end{aligned}
$$

Case 3: (the demand valley in the present period and the peak demand in the next period are not at equilibrium. The valley is greater than the peak).

Procedure P3:

$$
\begin{aligned}
& \mathrm{PR}_{\mathrm{t}}=\mathrm{D}_{\mathrm{t}}+\mathrm{D}_{\mathrm{t}}+1-\mathrm{PC}_{\mathrm{t}}+1 \\
& \mathrm{PRt}+1=\mathrm{PCt}+1
\end{aligned}
$$




\subsection{Heuristic 3 (H3)}

In this heuristic, effort is made to achieve the desired level of production oven three periods, by comparing the demand and production capacity of the periods. Fourteen cases are considered, each illustrate situations of valley and peak of demands for the three periods. Fourteen procedures are designed to achieve the desired production level and each procedure will be used to solve the problem of its case.

\subsection{Heuristic 4 (H4)}

In the fourth heuristic, attempt is made to attain the desired level of production over six periods and it also compares demand and production capacity. Sixty eight cases are considered, where each present situations of valley and peak of demands. Two procedures are formed to build a production plan.

\section{Dynamic Programming}

One of the mathematical programming techniques receive attention in the Operation Research is dynamic programming. It is a valuable planning technique and a problem solving tool (Anderson, 2003, Heizer, 2004, Lawrence, 2002). Essentially, dynamic programming is a mathematical optimization technique that can be applied to decision problems of a sequential nature. It involves the division of a large problem into a number of smaller problems. Each sub-problem should be solved in such a way that an overall optimal solution is obtained (Taylor, 2007, Wisniewski, 2006).

Dynamic programming is based on the principle of optimality. It suggests that: "an optimal policy must have the property that, regardless of the decision made to enter a particular state, the remaining decision must constitute an optimal policy for leaving that state" (Taylor, 2007).

In each process of applied dynamic programming, the functional equation governing the process was obtained by an application of the principle of optimality. It guarantees that a system is overall optimal if each stage is optimized with consideration being given only to the stage immediately preceding it.

One of the successful applications to which dynamic programming has been applied is multi-period production planning, and this is so because the determination of a production plan over a planning horizon of several time periods involves a series of sequential decisions. In such application, dynamic programming has proven to be very useful in relating to various production and inventory decisions over time (Anderson, 2003, Taylor, 2007).

In production planning, dynamic programming is often convenient to begin with output requirements for the period at the end of the planning horizon, as in backward induction, to determine what products must be produced in current period in order to optimize (for example minimize costs) over total horizon. The optimal production quantities, inventories, and so forth will determine the optimal combination to produce the subsequent results. The algorithm of applied model will be solved using software package of computerized dynamic programming model. The general recursion relationship of model as follow:

$$
\begin{aligned}
& F_{t}^{*}(S)=\min _{P R_{t}}\left[T P_{P R_{t}}+T S_{S_{t}}+F_{n-1}^{*}\left(S+P R_{t}-D_{t}\right)\right] \\
& =\min _{P R_{t}}\left[C S_{t}+C P_{t}\left(P R_{t}\right)+C H_{t}\left(S+P R_{t}-D_{t}\right)+\right. \\
& \left.F_{n-1}^{*}\left(S+P R_{t}-D_{t}\right)\right]
\end{aligned}
$$

for $\mathrm{t}=1,2, \ldots, \mathrm{N}$

where $\mathrm{S}=0,1,2, \ldots, 8$ and minimization is carried out over only non-negative values of the decision variable, PRt, in the range:

$\mathrm{D}_{\mathrm{t}}+\mathrm{S} \leq \mathrm{PR}_{\mathrm{t}} \leq \min$

\section{Numerical Examples}

Let us now consider some numerical examples to explain the difference between dynamic programming model and the heuristic model. Table 1 demonstrates the parameters of the problem including "production capacity, storage capacity, setup cost, production unit cost and holding unit cost".

Table 2 shows (36) a set of random numbers generated by a program on microcomputer system. The input data has been used to simulate pattern of the normal distribution which is applicable in many practical problems. Each set of data simulates customers' orders for six Periods. Input data will help us to explain how the production manager can 
operate in such a way that make good use of the fixed resources so as to get a smooth production level. This implies variation in aggregate inventory levels to fill the peaks and valleys in the aggregate customers' orders.

Table 1. Parameters of problem

\begin{tabular}{lc}
\hline Production capacity & 4 \\
Storage capacity & 8 \\
Setup cost & 4 \\
Production unit cost & 10 \\
Holding unit cost & 1 \\
\hline
\end{tabular}

Table 2. Set of random numbers for experiment plans

\begin{tabular}{|c|c|c|c|c|c|c|c|}
\hline \multirow{2}{*}{$\begin{array}{c}\text { Test } \\
\text { number }\end{array}$} & \multicolumn{6}{|c|}{ Demand in periods } & \multirow[t]{2}{*}{ Total } \\
\hline & 1 & 2 & 3 & 4 & 5 & 6 & \\
\hline 1 & 4 & 3 & 3 & 5 & 1 & 1 & 17 \\
\hline 2 & 3 & 3 & 5 & 1 & 1 & 3 & 16 \\
\hline 3 & 2 & 2 & 3 & 1 & 5 & 4 & 17 \\
\hline 4 & 3 & 2 & 2 & 4 & 4 & 4 & 19 \\
\hline 5 & 3 & 1 & 6 & 5 & 5 & 4 & 24 \\
\hline 6 & 2 & 2 & 4 & 1 & 5 & 6 & 20 \\
\hline 7 & 4 & 2 & 4 & 1 & 3 & 4 & 18 \\
\hline 8 & 3 & 4 & 4 & 1 & 6 & 4 & 22 \\
\hline 9 & 3 & 2 & 5 & 3 & 5 & 1 & 19 \\
\hline 10 & 2 & 6 & 2 & 6 & 4 & 4 & 24 \\
\hline 11 & 1 & 1 & 10 & 3 & 5 & 1 & 19 \\
\hline 12 & 3 & 2 & 5 & 6 & 4 & 3 & 23 \\
\hline 13 & 4 & 3 & 5 & 2 & 6 & 4 & 24 \\
\hline 14 & 1 & 2 & 7 & 6 & 3 & 5 & 24 \\
\hline 15 & 4 & 4 & 2 & 6 & 2 & 6 & 24 \\
\hline 16 & 4 & 4 & 4 & 1 & 5 & 3 & 21 \\
\hline 17 & 2 & 3 & 3 & 4 & 1 & 7 & 20 \\
\hline 18 & 1 & 6 & 4 & 3 & 3 & 5 & 22 \\
\hline 19 & 2 & 1 & 1 & 7 & 4 & 4 & 19 \\
\hline 20 & 1 & 1 & 1 & 5 & 4 & 2 & 14 \\
\hline 21 & 2 & 5 & 4 & 5 & 2 & 2 & 20 \\
\hline 22 & 2 & 2 & 2 & 6 & 4 & 3 & 19 \\
\hline 23 & 3 & 3 & 3 & 5 & 2 & 1 & 17 \\
\hline 24 & 1 & 7 & 3 & 4 & 2 & 2 & 19 \\
\hline 25 & 4 & 4 & 3 & 3 & 5 & 4 & 23 \\
\hline 26 & 1 & 2 & 9 & 3 & 5 & 3 & 23 \\
\hline 27 & 4 & 1 & 1 & 10 & 4 & 3 & 23 \\
\hline 28 & 4 & 1 & 1 & 1 & 1 & 10 & 18 \\
\hline 29 & 4 & 1 & 1 & 7 & 6 & 2 & 21 \\
\hline 30 & 4 & 1 & 3 & 3 & 6 & 2 & 19 \\
\hline 31 & 3 & 2 & 7 & 4 & 4 & 1 & 21 \\
\hline 32 & 1 & 6 & 3 & 4 & 2 & 1 & 17 \\
\hline 33 & 1 & 1 & 5 & 9 & 4 & 1 & 21 \\
\hline 34 & 4 & 1 & 5 & 2 & 1 & 7 & 20 \\
\hline 35 & 4 & 2 & 2 & 1 & 2 & 9 & 20 \\
\hline 36 & 3 & 2 & 3 & 4 & 3 & 5 & 20 \\
\hline
\end{tabular}




\section{Analysis of Output Data}

The objective of the output data is to explain the performance of the heuristic model with numerical data, and to compare its performance with the optimal result from dynamic programming model. This comparison will enable us to select which of them is better to employ.

Table 3. Comparison between total production and total cost of dynamic programming and heuristic models

\begin{tabular}{|c|c|c|c|c|c|}
\hline \multirow{2}{*}{$\begin{array}{c}\text { Test } \\
\text { number }\end{array}$} & \multirow{2}{*}{$\begin{array}{c}\text { Total } \\
\text { demand }\end{array}$} & \multicolumn{2}{|c|}{ Dynamic programming model } & \multicolumn{2}{|c|}{ Heuristic model } \\
\hline & & $\begin{array}{c}\text { Total } \\
\text { Production }\end{array}$ & Total cost & $\begin{array}{c}\text { Total } \\
\text { production }\end{array}$ & Total cost \\
\hline 1 & 17 & 17 & 192 & 17 & 192 \\
\hline 2 & 16 & 16 & 182 & $\underline{15}$ & $\underline{171}$ \\
\hline 3 & 17 & 17 & 193 & 17 & 193 \\
\hline 4 & 19 & 19 & 212 & 19 & 212 \\
\hline 5 & 24 & 24 & 272 & 24 & 272 \\
\hline 6 & 20 & 20 & 227 & 20 & 227 \\
\hline 7 & 18 & 18 & $\underline{202}$ & 18 & 203 \\
\hline 8 & 22 & 22 & 246 & 22 & 246 \\
\hline 9 & 19 & 19 & 216 & $\underline{18}$ & $\underline{205}$ \\
\hline 10 & 24 & 24 & 268 & 24 & 268 \\
\hline 11 & 24 & 24 & 274 & 24 & 274 \\
\hline 12 & 23 & 23 & 260 & 23 & 260 \\
\hline 13 & 24 & 24 & 267 & 24 & 267 \\
\hline 14 & 24 & 24 & 275 & $\underline{19}$ & $\underline{213}$ \\
\hline 15 & 24 & 24 & 268 & 24 & 268 \\
\hline 16 & 21 & 21 & 235 & 21 & 235 \\
\hline 17 & 20 & 20 & 227 & 20 & 227 \\
\hline 18 & 22 & 22 & 247 & 22 & 247 \\
\hline 19 & 19 & 19 & 214 & 19 & 214 \\
\hline 20 & 14 & 14 & 162 & 14 & 162 \\
\hline 21 & 20 & 20 & 226 & 20 & 226 \\
\hline 22 & 19 & 19 & 214 & 19 & 214 \\
\hline 23 & 17 & 17 & 192 & 17 & 192 \\
\hline 24 & 19 & 19 & 215 & 19 & 215 \\
\hline 25 & 23 & 23 & 255 & 23 & 255 \\
\hline 26 & 23 & 23 & 263 & 23 & 263 \\
\hline 27 & 23 & 23 & 263 & 23 & 263 \\
\hline 28 & 18 & $\underline{16}$ & $\underline{194}$ & 18 & 210 \\
\hline 29 & 21 & 21 & 243 & 21 & 243 \\
\hline 30 & 19 & 19 & 217 & $\underline{18}$ & $\underline{202}$ \\
\hline 31 & 21 & 21 & 238 & 21 & 238 \\
\hline 32 & 17 & 17 & 193 & 17 & 193 \\
\hline 33 & 21 & 21 & 248 & 21 & 248 \\
\hline 34 & 20 & 20 & 228 & 20 & 228 \\
\hline 35 & 20 & $\underline{19}$ & $\underline{228}$ & 20 & 230 \\
\hline 36 & 20 & 20 & 225 & 20 & 225 \\
\hline
\end{tabular}


From Table 3 we can identify the following:

- In the dynamic programming model, all customers' orders are met with optimal total cost in 34 tests. In tests numbers $28 \& 35$ (underlined) it does not meet all customers' orders.

- In the heuristic model, we obtained the same result from dynamic programming model in 29 tests. In tests number 2, 9, 14, 30, (underlined) heuristic does not meet all customers' orders. In test number 7 (underlined) we got a total cost more than optimal.

\section{Conclusions}

- From the results of this work we can conclude that heuristic methods gives better support in problems of production planning.

- Moreover, there are a number of reasons to support out our preference for heuristic methods. The most important are:

- Development time and cost of heuristic methods are less than exact optimization model;

- Heuristic methods requires substantially less time to solve a problem either by computer or by manually;

- Heuristic methods can often be implemented and understood without undue difficulty and this is attributable to their simplicity. This character will enable managers to establish good communication with other managers. Furthermore, it will encourage them to extend delegation of authority;

- It tends to be more flexible than exact algorithms, which are fairly restrictive in terms of both their assumption and the types of constraints they can handle. It can be more responsive to change. A production manager faces \& operates within a dynamic environment. Exact algorithms, because of their static nature, lose some of their effectiveness within such as environment. The heuristic method, on other hand, can often be formulated to adopt more easily to these changes.

- Heuristic methods can be used as useful tools for knowledge capture through building a link between expert managers and information technology to transform tacit knowledge to explicit knowledge (Alsameraai, 2003, Becerra-Fernandez, 2004).

- Due to time limitations, we could not test the heuristics developed in this paper on an organization from the Arabian industry. Therefore, we recommend future researches that test these heuristics in field, so we can explore the benefits and limitation of applying heuristics methods in solving the problems of aggregate production planning.

\section{References}

Ahmed, A.D. (1998). Using Quantitative Methods in Decision - Making. Journal of Public Management, 38(3).

Alqeisy, M. (2003). The Role of Information Technology in Improving the Process of Administrative Decision Making. Unpublished (MBA), Jordanian University.

Alsameraai, H. (1999). Workers Attitudes for Using Quantitative Methods in Decision Making. Journal of Public Management, 38(4).

Alshaikh, F.N. (1993). The Application of Quantitative Analysis Technique in Manufacturing Organizations. International Journal of Information Management, (12).

Alvarado-Valencia, J. A., \& Barrero, L. H. (2014). Reliance, trust and heuristics in judgmental forecasting. Computers in Human Behavior, 36. http://dx.doi.org/10.1016/j.chb.2014.03.047

Anderson, D.R. (2003). An Introduction to Management Science (10th ed.). South- Western, Ohio.

Bang, D., Fusaroli, R., Tylén, K., Olsen, K., Latham, P.E., Lau, Y.F., .. Bahrami, B. (2014). Does interaction matter? Testing whether a confidence heuristic can replace interaction in collective decision-making. Consciousness and Cognition, 26. http://dx.doi.org/10.1016/j.concog.2014.02.002

Becerra-Fernandez, I. (2004). Knowledge Management Challenges, Solution, and Technologies. Pearson Education, Upper Saddle River, NJ.

Gaither, N. (2002). Operations Management (9th ed.). South- Western, Ohio.

Goodwin, P. (2004). Decision Analysis for Management Judgment (3rd ed.). John Wiley \& Sons ltd, Southern Gate. 
Guignar, M. (1992). Appling Modified Coefficient Reduction Method to a Dynamic Scheduling Model. Eur. J. Operat. Res., 56(1).

Hauser, J.R. (2014). Consideration-set heuristics, Journal of Business Research, 67(8) http://dx.doi.org/10.1016/j.jmsy.2014.09.006

Heizer, J. (2004). Operations Management (7th ed.). Pearson Education, Upper Saddle River, NJ.

Hillier, F. (1990). Introduction to Operations Research. Mc Graw- Hill, New York.

Hu, Z., \& Wang, X.T. (2014). Trust or not: Heuristics for making trust-based choices in HR management. Journal of Business Research, 67(8). http://dx.doi.org/10.1016/j.jbusres.2014.02.017

Klein, D. (1991). Simple Heuristic Methods for Network Routing: A case Study. Omega, 18(2/3).

Krajewski, L.J. (2002). Operations Management Strategy and Analysis (6th ed.). Pearson Education, Upper Saddle River, NJ.

Lawrence, Jr. J.A. (2002). Applied Management Science (2nd ed.). John Wiley \& Sons ltd, Southern Gate.

Leong, G. (1990). A Sequencing Heuristic for Dependent Setups in a Bath Process Industry. Omega, 18(18).

Maashi, M., Kendall, G., \& Özcan, E. (2015). Choice function based hyper-heuristics for multi-objective optimization. Applied Soft Computing, 28.

Moghaddam, A., Yalaoui, F., \& Amodeo, L. (2015). Efficient meta-heuristics based on various dominance criteria for a single-machine bi-criteria scheduling problem with rejection. Journal of Manufacturing Systems, 34. http://dx.doi.org/10.1016/j.jmsy.2014.09.006

Naylor, J. (2002). Introduction to Operation Management (2nd ed.). Pearson Education Limited, Edinburgh Gate.

Pendharkar, P.C. (2015). Cost minimizing target setting heuristics for making inefficient decision-making units efficient. International Journal of Production Economics, 162. http://dx.doi.org/10.1016/j.ijpe.2014.12.023

Render, B. (2003). Managerial Decision Modeling. Pearson Education, Upper Saddle River, NJ.

Smith, G.F. (1990). Heuristic Methods for the Analysis of Managerial Problems. Omega, 18(6).

Taylor, III, B. W. (2007). Introduction to Management Science (9th ed.). Pearson Education, Upper Saddle River, NJ.

Teale, M. (2003). Management Decision - Making. Pearson Education Limited, Edinburgh Gate.

Turban, E. (2003). Decision Support and Expert Systems. Macmillan, New York.

Wästlund, E., Otterbring, T., Gustafsson, A., \& Shams, P. (2015). Heuristics and resource depletion: eye-tracking customers' in situ gaze behavior in the field. Journal of Business Research, 68(1). http://dx.doi.org/10.1016/j.jbusres.2014.05.001

Wisniewski, M. (2006). Quantitative Methods for Decision Makers (4th ed.). Pearson Education Limited, Edinburgh Gate.

Yusef, R.D. (1991). Decision Making Methods in Manufacturing and Service Organizations. Arabic Journal of Management, 15(1). 